\title{
Влияние способа деактивации поверхности стеклянного капилляра на индексы удерживания производных анилина
}

\author{
Набивач В.М., Герасименко В.А., Рунова Г.Г., Кушнир И.П. \\ Украинский государственный химико-технологический университет, Днепр, Украина
}

Поступила в редакцию 7.11.2017 г.

\begin{abstract}
Измерены индексы удерживания производных анилина на капиллярных колонках с различными способами деактивации внутренней поверхности капилляра. Показано, что деактивация неэкстрагируемым слоем полиэтиленгликоля существенным образом влияет на хроматографические свойства неполярной неподвижной фазы - метилсилоксана. Установлено, что межлабораторный пересчет индексов удерживания производных анилина возможен только для узких гомологических рядов.
\end{abstract}

Ключевые слова: газовая хроматография, межлабораторный пересчет индексов удерживания анилинов.

\section{Influence of deactivating method of the inner glass capillars surface on the aniline derivatives retention indices}

\author{
Nabivach V.M., Gerasimenko V.A., Runova G.G., Kushnir I.P. \\ Ukrainian State University of Chemical Technology, Dnipro, Ukraine
}

The article deals with the study of retention indices of aniline derivatives which were measured on glass capillary columns with different ways of deactivating the inner surface of the capillary. One of the columns was prepared by deactivating the inner surface of the glass capillary by the method of silanization. The other column was deactivated by forming an unextractable polyethylene glycol layer. Then, the same apolar stationary phase of methylsiloxane OV-101 was applied to both capillaries. It is shown that the deactivation of the glass capillary by an unextractable layer of polyethylene glycol significantly affects the chromatographic properties of the apolar stationary phase. This effect leads to the appearance of an intercolumnal difference in the retention indices of aniline derivatives. It was found that the value of the inter-column difference in the retention indices is not constant. It was shown that alkyl substituents perform a screening function during the interaction of alkylaniline molecules with a stationary phase. Therefore, an increase in the size and number of alkyl groups in alkylaniline molecules leads to a decrease in the difference between their retention indices on the columns with different deactivation methods. Non-alkyl substituents cause an increase in the polarization of molecules of aniline derivatives. As a result, aniline derivatives with non-alkyl substituents are more strongly retained on a column deactivated by polar polyethylene glycol. In this case, increasing the size of the substituent leads to an increase in the inter-column difference in the retention indices. Large values of the intercolumn difference in retention indices measured on columns with different methods of treating the surface of capillaries exclude their direct use for identification purposes. Correlative and predictive possibilities of intercolumn (interlaboratory) recalculation of retention indices of alkylanilines measured on the same stationary phase, but with different ways of treating the inner surface of capillary columns, were investigated. With the use of the entire set of N-, N,N- and C-alkylanilines, a correlation has been obtained that has a low correlation level (standard deviation of 7.2 i.u.). The use of only narrow homologous series as base compounds made it possible to significantly improve the correlation capabilities of intercolumn (interlaboratory) conversion of the retention indices of alkylanilines. The obtained 
equations were used to estimate the accuracy of the predictive calculation of the retention indices of the nearest homolog of the base series of compounds, as well as representatives of other homologous series. The accuracy of the calculations was estimated as the difference between the calculated and experimental values of the retention indices. It is established that the retention indices of the nearest homologue are determined with acceptable accuracy. However, for representatives of other homologous series, the calculation error considerably exceeds the value of the generally accepted criterion of identification accuracy. Consequently, intercolumn (interlaboratory) recalculation of retention indices of alkylanilines measured on columns with different methods of surface treatment of capillaries for identification purposes is possible only within narrow homologous series.

Keywords: gas chromatography, interlaboratory count of anilines retention indices.

\section{Введение}

Газохроматографические индексы удерживания являются наиболее надежными параметрами для бесстандартной идентификации анализируемых соединений. Их широкому использованию в аналитической практике препятствует межлабораторная невоспроизводимость, обусловленная рядом факторов, в том числе адсорбционной способностью поверхности сорбентов. В капиллярной газовой хроматографии функцию твердого носителя выполняет внутренняя поверхность капилляра. Для получения высокоэффективных колонок внутреннюю поверхность обрабатывают различными способами.

Опубликованные в литературе индексы удерживания углеводородов на неполярных неподвижных фазах [1] показывают хорошее совпадение даже для капиллярных колонок, изготовленных из различных материалов (кварц, стекло, нержавеющая сталь) Показано [2], что индексы удерживания хлор- и бромпроизводных анилина проявляют зависимость от толщины пленки неполярной неподвижной фазы. Адсорбцию ряда производных анилина исследовали также методом высокоэффективной жидкостной хроматографии [3]. Однако для полярных сорбатов отсутствуют систематизированные данные по влиянию сорбционных свойств колонки на индексы удерживания.

Целью настоящей работы явилось изучение влияния способа обработки поверхности стеклянных капилляров на удерживание полярных слабоосновных соединений - производных анилина.

\section{Эксперимент}

Газохроматографический анализ проводили на приборах «Цвет-100» и «ЛХМ-80» с пламенно-ионизационным детектором. В качестве неподвижной фазы применяли широко используемый метилсилоксан OV-101. Одна из колонок приготовлена деактивацией внутренней поверхности стеклянного капилляра методом силанизации [4], другая - формированием неэкстрагируемого слоя полиэтиленгликоля [5]. В качестве газа-носителя применяли азот. Температура колонки была 120 и $140^{\circ} \mathrm{C}$, температура испарителя $250^{\circ} \mathrm{C}$, давление газа-носителя на входе в колонку составляло 0.04 МПа. Деление потока газа-носителя на входе в колонку было 1:130, объем пробы составлял 0.5 мкл.

Для определения индексов удерживания производные анилина вводили в испаритель хроматографа в смеси с соответствующими $\boldsymbol{H}$-алканами. В пробу добавляли метан для определения мертвого времени удерживания. Для каждой смеси снимали не менее четырех хроматограмм. Время удерживания компонентов измеряли по максимумам их пиков секундомером с точностью \pm 0.05 с. В этих условиях ошибка оп- 
ределения индексов удерживания не превышала 0.5 е.и.. Измерены индексы удерживания широкого круга N- и С-замещенных производных анилина (табл. 1).

Таблица 1. Индексы удерживания и их разность $\Delta$ производных анилина на метилсилоксане OV-101 при $120^{\circ} \mathrm{C}$, измеренные на стеклянных капиллярных колонках с различными способами деактивации поверхности

\begin{tabular}{|c|c|c|c|}
\hline \multirow{2}{*}{ Соединение } & \multicolumn{2}{|c|}{ Способ деактивации } & \multirow{2}{*}{$\Delta$, е.и. } \\
\hline & силанизация & полиэтиленгликолем & \\
\hline Анилин & 957.8 & 990.4 & 32.6 \\
\hline 2-Метил- & 1050.0 & 1079.1 & 29.1 \\
\hline 3-Метил- & 1056.2 & 1085.8 & 29.6 \\
\hline 4-Метил- & 1051.0 & 1080.6 & 29.6 \\
\hline 2-Этил- & 1128.5 & 1154.1 & 25.6 \\
\hline 3-Этил- & 1146.0 & 1174.7 & 28.7 \\
\hline 4-Этил- & 1142.8 & 1170.2 & 27.4 \\
\hline 4-Изопропил- & 1203.4 & 1227.4 & 24.0 \\
\hline 4-mpem-Бутил- & 1269.6 & 1293.4 & 23.8 \\
\hline 2,4-Диметил- & 1141.7 & 1164.9 & 23.2 \\
\hline 2,6-Диметил- & 1143.1 & 1163.6 & 20.5 \\
\hline 2,4,6-Триметил- & 1233.5 & 1252.0 & 18.5 \\
\hline N-Метил- & 1044.2 & 1063.8 & 19.6 \\
\hline N-Этил- & 1107.2 & 1122.1 & 14.9 \\
\hline N-Изопропил- & 1133.1 & 1143.2 & 10.1 \\
\hline N-Пропил- & 1200.0 & 1213.6 & 13.6 \\
\hline N-Бутил- & 1300.3 & 1313.0 & 12.7 \\
\hline N-Пентил- & 1399.4 & 1411.8 & 12.4 \\
\hline N-Гексил- & 1499.2 & 1510.5 & 11.3 \\
\hline N,N-Диметил- & 1076.2 & 1084.7 & 8.5 \\
\hline N,N-Диэтил- & 1204.7 & 1211.0 & 6.3 \\
\hline N,N-Дипропил- & 1363.1 & 1367.7 & 4.6 \\
\hline N,N-Дибутил- & 1537.0 & 1541.8 & 4.8 \\
\hline 4-Метокси- & 1183.4 & 1233.8 & 50.4 \\
\hline 4-Этокси- & 1253.5 & 1294.1 & 40.6 \\
\hline 4-Хлор- & 1168.1 & 1233.8 & 65.7 \\
\hline 4-Бром- & 1255.8 & 1325.9 & 70.1 \\
\hline 4-Йод- & 1357.0 & 1437.3 & 80.3 \\
\hline
\end{tabular}

\section{Обсуждение результатов}

Полученные данные указывают на существенную разность в параметрах удерживания на колонках с различными способами деактивации поверхности капилляра. Более высокие значения индексов удерживания получены на колонке, внутренняя поверхность которой дезактивирована полиэтиленгликолем. Следует отметить, что величина разности $\Delta$ в индексах удерживания, измеренных на колонках с различными способами обработки поверхности, не является постоянной (табл. 1).

Так, величина $\Delta$ для моноалкилзамещенных анилина линейно снижается при увеличении размеров алкильного радикала, выраженного с помощью конического угла заместителя $\Theta$ [6]. Увеличение экранирования углеродных атомов фенильного кольца алкильными заместителями незначительно влияет на величину $\Delta$. Наличие незамещенной (неэкранированной) аминогруппы в молекулах углеродзамещенных С-алкиланилинов приводит к большей величине разности в индексах удерживания 
$\Delta$, чем экранирование атома азота аминогруппы в случае $\mathrm{N}$-алкилпроизводных. Однако для $\mathrm{N}$-алкилпроизводных анилина зависимость величины $\Delta$ от конического угла $\Theta$, создаваемого алкильным заместителем, выражается более четко (рис. 1).

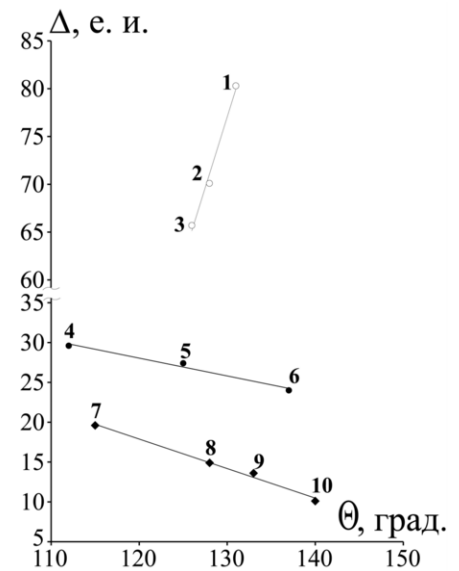

Рис. 1. Зависимость разности индексов удерживания производных анилина $\Delta$, измеренных на колонках с различными способами деактивации поверхности, от конического угла $\Theta$ замещающей группы: 1 - 4-йоданилин; 2 - 4-броманилин; 3 - 4-хлоранилин; 4 - 4-метиланилин; 5 4-этиланилин; 6 - 4-изопропиланилин; 7$\mathrm{N}$-метиланилин; 8 - N-этиланилин; 9 - Nпропиланилин; 10 - N-изопропиланилин.

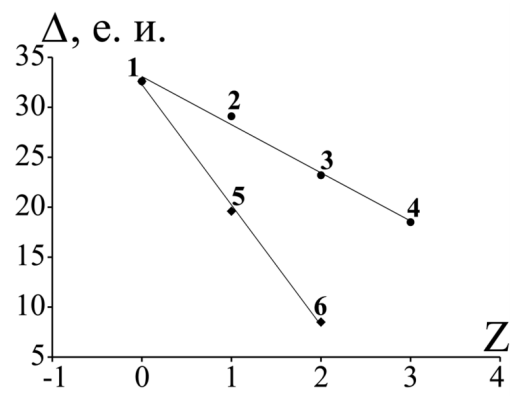

Рис. 2. Зависимость разности индексов удерживания алкиланилинов $\Delta$, измеренных на колонках с различными способами деактивации поверхности, от числа метильных групп Z: 1 - анилин; 2 - 2-метиланилин; 3 - 2,4диметиланилин; 4 - 2,4,6-

триметиланилин; 5 - N-метиланилин; 6 - N,N-диметиланилин.

Для полиалкилзамещенных анилина указанные закономерности проявляются еще более резко. Так, величина $\Delta$ заметно снижается при увеличении числа метильных групп, присоединенных к фенильному кольцу. Еще более круто происходит снижение величины разности в индексах удерживания $\Delta$ для соединений с увеличивающимся количеством метильных заместителей у атома азота в аминогруппе (рис. 2). Следовательно, алкильные заместители выполняют экранирующую функцию в процессе взаимодействия молекул алкиланилинов с неподвижной фазой. Поэтому увеличение размеров и количества алкильных групп приводит к уменьшению разности между индексами удерживания на колонках с различными способами деактивации.

Неалкильные заместители вызывают увеличение поляризации молекул производных анилина. Так, дипольные моменты пара-метоксианилина (1.8-1.84 D) и nара-галогенанилинов (2.82-3.00 D) явно превышают дипольный момент молекулы nара-метиланилина (1.24-1.52 D) [7]. И, как следствие, производные анилина с неалкильными заместителями сильнее удерживаются на колонке, деактивированной полярным полиэтиленгликолем (табл.1). В этом случае увеличение размеров заместителя приводит к увеличению разности в индексах удерживания $\Delta$ (рис. 1 ).

Большие значения величины межколоночной разности в индексах удерживания исключают их непосредственное использование для идентификации. Для преодоления этих препятствий предложено [8] использовать корреляционные соотношения вида

$$
\mathrm{I}_{1}=\mathrm{A}+\mathrm{B} \mathrm{I}_{2}
$$

где $\mathrm{I}_{1}$ и $\mathrm{I}_{2}$ - индексы удерживания, измеренные на разных колонках (в разных лабораториях). 
Нами выполнена оценка корреляционных и прогнозирующих возможностей соотношения (1) для двух массивов индексов удерживания алкиланилинов, измеренных на одной и той же неподвижной фазе, но с различными способами обработки внутренней поверхности капиллярных колонок. При использовании всей совокупности N-, N,N- и C-алкиланилинов получено соотношение (1), обладающее невысоким уровнем корреляции (стандартное отклонение составило 7.2 е.и). Применение в качестве базовых соединений представителей узких гомологических рядов (табл. 2) позволило существенно улучшить корреляционные возможности соотношения (1).

Таблица 2. Оценка корреляционных и прогнозирующих возможностей уравнения (1) для алкилпроизводных анилина

\begin{tabular}{|c|c|c|c|c|c|}
\hline \multirow{2}{*}{$\begin{array}{c}\text { Базовые соеди- } \\
\text { нения }\end{array}$} & \multicolumn{3}{|c|}{ Параметры уравнения (1) } & \multirow{2}{*}{ Проверочные соединения } & \multirow{2}{*}{$\delta$, е.и. } \\
\hline & A & B & s, e.и. & & \\
\hline \multirow{3}{*}{$\begin{array}{l}\text { С-Метил- } \\
\text { анилины }\end{array}$} & \multirow{3}{*}{93.94} & \multirow{3}{*}{0.939} & \multirow{3}{*}{0.6} & $\begin{array}{c}\text { 4-Этиланилин } \\
\text { (ближайший гомолог) }\end{array}$ & 3.6 \\
\hline & & & & N-Метиланилин & 10.2 \\
\hline & & & & N,N-Диметиланилин & 19.4 \\
\hline \multirow{3}{*}{$\begin{array}{l}\text { N-Алкил- } \\
\text { анилины }\end{array}$} & \multirow{3}{*}{43.31} & \multirow{3}{*}{0.976} & \multirow{3}{*}{1.7} & $\begin{array}{c}\text { N-Пентиланилин } \\
\text { (ближайший гомолог) }\end{array}$ & 2.9 \\
\hline & & & & 4-Этиланилин & 11.7 \\
\hline & & & & N,N-Диметиланилин & 8.8 \\
\hline \multirow{3}{*}{$\begin{array}{c}\text { N,N-Диалкил- } \\
\text { анилины }\end{array}$} & \multirow{3}{*}{22.85} & \multirow{3}{*}{0.987} & \multirow{3}{*}{0.4} & $\begin{array}{l}\text { N,N-Дибутиланилин } \\
\text { (ближайший гомолог) }\end{array}$ & 2.7 \\
\hline & & & & 4-Этиланилин & 20.0 \\
\hline & & & & N-Метиланилин & 10.8 \\
\hline
\end{tabular}

Полученные уравнения использовали для оценки точности прогнозирующего расчета индексов удерживания ближайшего гомолога базового ряда соединений, а также представителей других гомологических рядов. Точность расчетов оценивали с помощью величины $\delta$, определяемой как разность между расчетными и экспериментальными значениями индексов удерживания.

Анализ величины $\delta$ (табл. 2) показывает, что удерживание ближайшего гомолога определяется с приемлемой точностью. Однако для представителей иных гомологических рядов ошибка расчета значительно превышает величину общепринятого критерия точности идентификации [9]. Следовательно, высокие корреляционные и прогнозирующие возможности соотношения (1) можно ожидать только для узких гомологических рядов соединений.

\section{Заключение}

Таким образом, индексы удерживания производных анилина, измеренные на колонках с различными способами деактивации внутренней поверхности капилляра, могут существенно различаться. Величина разности в индексах удерживания при этом не является постоянной, она зависит от состава, размеров и числа заместителей. Межлабораторный (межколоночный) пересчет индексов удерживания исследованных соединений в соответствии с уравнением (1) для целей идентификации возможен только для узких гомологических рядов. 


\section{Список литературы}

1. Бонева Ст., Папазова Д., Димов Н. // Год. Висш. хим.-технол. ин-т. Бургас. 1983. Т. 18. № 2.C. 143-149.

2. Груздев И.В., Алферова М.В., Кондратенок Б.М., Зенкевич И.Г. // Журнал аналитической химии. 2011. Т. 66. № 5. С. 519-524.

3. Ланин С.Н., Рычкова С.А., Виноградов А.Е., Ланина К.С. и др. // Известия Академии наук. Серия химическая. 2016. № 1. С. 110-119.

4. Берлизов Ю.С. Березкин В.Г., Королев А.А., Набивач В.М. и др. // Журнал аналитической химии. 1986. Т. 41. № 3. С. 519-522.
5. Blomberg L. // J. Chromatogr. 1975. Vol. 115. No 2. pp. 365-372.

6. Имянитов Н.С. // Журнал органической химии. 1987. Т. 23. №5. С. 916-921.

7. Осипов О.А., Минкин В.И. Справочник по дипольным моментам. М. Высшая школа. 1965. $264 \mathrm{c}$.

8. Вигдергауз М.С., Пахомова В.И. // Заводская лаборатория. 1986. Т. 52. № 7. С. 1922.

9. Светлова Н.И., Григорьева Д.Н., Журавлева И.Л., Головня Р.В. // Журнал аналитической химии. 1984. Т. 39. № 7. С. 1292-1296.

\section{References}

1. Boneva S., Papazova D., Dimov N. God. Vissh. Khim.-Tekhnol. Inst., Burgas, 1983, Vol.18, No 2, pp. 143-149 .

2. Gruzdev I.V., Alferova M.V., Kondratenok B.M., Zenkevich I.G., J. of Analytical Chemistry, 2011, Vol. 66, No 5, pp. 519-524.

3. Lanin S.N., Rychkova S.A., Vinogradov A.E., Lanina K.C., Shatalov I.A. News of Academy Sciences. Chemical series, 2016, No 1, pp. 110-119.

4. Berlizov Yu.S., Berezkin V.G., Korolev A.A., Nabivach V.M. et al., J. of Analytical Chemistry, 1986, Vol. 41, No 3, pp. 519-522.

Набивач Валентин Михайлович - профессор кафедры технологии неорганических веществ и экологии, д.Х.н., Украинский государственный химикотехнологический университет, г. Днепр, Украина

Герасименко Владимир Александрович - доцент кафедры охраны труда и безопасности жизнедеятельности, к.Х.н., Украинский государственный химико-технологический университет, г. Днепр, Украина

Рунова Галина Геннадиевна - ассистент кафедры охраны труда и безопасности жизнедеятельности, Украинский государственный химикотехнологический университет, Днепр, Украина

Кушнир Ирина Петровна - ассистент кафедры охраны труда и безопасности жизнедеятельности, Украинский государственный химикотехнологический университет, Днепр, Украина
5. Blomberg L., J. Chromatogr., 1975, Vol. 115, No 2, pp. 365-372.

6. Imianitov N.S., J. of Organical Chemistry, 1987, Vol. 23, No5, pp. 916-921.

7. Osipov O.A., Minkin V.I., Spravochnik po dipolnim momentam. M.,Vysshaya shkola Publ., 1965, 264 p.

8. Vigdergauz M.S., Pakhomova V.I. Zavodskaya laboratoriya, 1986, Vol. 52, No 7, C. 1922.

9. Svetlova N.I., Grigoreva D.N., Zhuravleva I.L., Golovnya R.V. J. of Analytical Chemistry, 1984, Vol. 39, No 7, pp. 1292-1296.

Nabivach Valentin M. - prof, grand Ph.D. (chemistry), department of non-organic substances technology and ecology, Ukrainian State University of Chemical Technology, Dnipro, Ukraine, vmnabivach@gmail.com

Gerasimenko Vladimir A. - Ph.D. (chemistry), associate prof., department of labour protection and life safety, Ukrainian State University of Chemical Technology, Dnipro, Ukraine, roninmvg@gmail.com

Runova Galina G. - assistant, department of labour protection and life safety, Ukrainian State University of Chemical Technology, Dnipro, Ukraine, galinaru@i.ua

Kushnir Irina P. - assistant, department of labour protection and life safety, Ukrainian State University of Chemical Technology, Dnipro, Ukraine 